\title{
Literatura en guerra: la narrativa contemporánea en Centroamérica ${ }^{1}$
}

\author{
Margarita Rojas $\mathrm{G}^{2}$ \\ Universidad Nacional, Costa Rica
}

\begin{abstract}
resumen
El estudio analiza el panorama de la narrativa centroamericana contemporánea, escrita por autores nacidos entre 1950 y 1964. Se trata de una generación que ha optado por una estética narrativa novedosa, claramente distinguible de grupos anteriores. Dos rasgos se destacan en sus perspectivas literarias: por un lado, la temática urbana contemporánea con una compleja red de condiciones materiales e interacciones sociales; por otro, el particular tratamiento del tiempo histórico, con sus específicas alusiones a acontecimientos de la historia social y poética. Se muestra que en todos los casos, estas son manifestaciones de una «literatura» de guerra, no de la posguerra.
\end{abstract}

\begin{abstract}
This study analyzes the panorama of contemporary Central American narrative, written by authors born between 1950 and 1964. It is a generation that has opted for innovative narrative esthetics, which is clearly distinguishable from that used by previous groups. Two characteristics stand out in their literary perspectives: 1 . contemporary urban themes with a complex network of material conditions and social interactions; 2 . the particular treatment of the historical period with its allusions to events of social and poetic history. In all cases, it is clear that they are manifestations of war, rather than postwar, literature.
\end{abstract}

Palabras clave: narrativa centroamericana, literatura de la guerra, novela histórica, literatura urbana

Keywords: Central American narrative, war literature, historical novel, urban literature

1 Conferencia leída en el XX Congreso Internacional de Literatura Centroamericana (ciLca) 2012. Recibido: 3 de enero de 2011; aceptado: 12 de enero de 2011.

2 Escuela de Literatura y Ciencias del Lenguaje. Correo electrónico: mmrojasg@ice.co.cr

$$
L_{\text {etras }} 49 \text { (2011), ISSN 1409-424X }
$$


Los apuntes que siguen a continuación se refieren a novelas, cuentos y relatos publicados en un período delimitado, entre 2006 y 2012. Durante estos años fallecieron tres escritores centroamericanos cuya obra también entraría en el corpus analizado. Por este motivo, antes de iniciar propiamente la lectura, quisiera rendir un sencillo homenaje a ellos.

En 2007 murió en Nicaragua, donde había vivido últimamente, Franz Galich, nacido en Guatemala 56 años atrás. Autor de tres libros de cuentos, publicó el primero, Ficcionario inédito, a sus 28 años; luego aparecieron La princesa de Onix y otros relatos en 1989, y en 2003 El ratero y otros relatos. Se dio a conocer internacionalmente al obtener el premio «Rogelio Sinán» de Panamá, en 1999 con la novela Managua Salsa City (;Devórame otra vez!), después de la cual publicó dos más: En este mundo matraca, en 2005, y $Y$ te diré quién eres (Mariposa traicionera), al año siguiente.

En 2008, falleció en Honduras Roberto Castillo, cuando contaba con 58 años. Después de estudiar en este país, fue catedrático de filosofía durante más de veinte años en la Universidad Nacional Autónoma de Honduras. Publicó la mayor parte de sus libros en la década de 1980, principalmente cuento y novela, y su vasta novela La guerra mortal de los sentidos en 2002. Recibió el Premio «Plural», de cuento, en México (1984) y el Premio Nacional de Literatura «Ramón Rosa» en 1991.

También es de lamentar la muerte del prolífico escritor guatemalteco, Rafael Menjívar Ochoa, nacido en 1959 y fallecido en 2011. De Menjívar se resalta la fundación de la Casa del escritor en 2001; fue autor, además, de un libro de poesía, de al menos dos libros ensayísticos, así como de ocho novelas, varias traducidas, principalmente al francés, y dos merecedoras de premios internacionales: Historia del traidor de Nunca Jamás, que ganó el Premio Latinoamericano de novela Educa en 1984, y la novela negra titulada Los años marchitos de 1990, que ganó el Premio latinoamericano de novela Ramón del Valle Inclán. 


\section{El mapa narrativo de 2006 a 2012}

¿Qué se ha publicado en el último sexenio, desde 2006 hasta ahora?

Desde hace varios me he dedicado al estudio de la narrativa contemporánea latinoamericana; por esta entiendo no las obras que han aparecido recientemente en todos los países sino las que han publicado los escritores nacidos entre 1950 y 1964. Esta es la generación que domina actualmente el panorama y por eso interesa especialmente su estudio. Es claro que también se publican otras obras, de autores de más edad o más jóvenes y precisamente esta dinámica es la que establece los conflictos estéticos.

Producto de esas investigaciones es el libro publicado en 2006 La ciudad y la noche ${ }^{3}$. En este planteé un modelo que explicaría supuestamente la opción estética de los narradores latinoamericanos nacidos entre esos años, incluidos los centroamericanos. Cuando se estudian los textos delimitados de esta manera, se revela un conjunto de rasgos asombrosamente semejantes y, al mismo tiempo, se muestran sus oposiciones con los de grupos anteriores.

Dundos. A diferencia de los escritores nacidos en la década de 1940, con los de los años 50 se abandona definitivamente la búsqueda de las utopías; la indagación acerca la identidad — local, nacional o regional, de grupos o de sexos- que caracterizaba la literatura de los escritores anteriores, desapareció de las preocupaciones literarias de los nuevos. Los acontecimientos de las obras desdeñan el campo y todo rasgo que identifique un lugar particular: estos autores reaccionan contra la imagen «folclórica» del continente (la reducción de América Latina a «lo indígena», lo folclórico) frente a la cual oponen el espacio de la urbe contemporánea mundial. Los ambientes predilectos por todos son invariablemente los propios de las urbes contemporáneas: cantinas y tabernas, ambientes subterráneos y lugares

3 Margarita Rojas G., La ciudad y la noche. La nueva narrativa latinoamericana (San José: Farben, 2006). 
ocultos. Del código que domina esta literatura forman parte el ambiente urbano nocturno, las relaciones basadas en la violencia, y el juego entre la traición y la lealtad. El género preferido es el relato policíaco, que también reaparece en el cine contemporáneo.

Es necesario observar, en primer lugar, que en este corpus hay autores ya estudiados y autores que recién se incorporan a los géneros del cuento o la novela. Entre estos últimos, podemos empezar por la panameña Consuelo Tomás, quien se había destacado sobre todo en el campo de la lírica, con dos premios nacionales y unos diez libros; un premio con la única obra de teatro publicada, un premio con un libro de cuento, y hace un par de años gana el premio nacional otra vez pero con su primera novela. Se trata de Lágrima de dragón, una narración sencilla, con pasajes que podrían considerarse propios del relato para niños. Muy pocas marcas temporales o espaciales ayudan a ubicar la historia en una temporalidad específica ni en una ciudad particular. Solo se logra determinar que se trata del pasado de una ciudad frente al mar, que tuvo una importante inmigración desde China y una violenta epidemia que diezmó la población. Por los nombres de los personajes y otros pocos datos, parece ubicarse en el período colonial panameño.

El acontecimiento inicial es el encuentro de un niño con la muerte, materializada en un cadáver que están terminando de comer unos buitres:

Detenido en mitad de la calle (...) Fang Lu observa cómo los buitres devoran con fruición las entrañas de alguien que se convirtió en materia inerte y comestible. No pestañea, no se tapa la nariz ante el hedor, sólo trata de comprender. Esto que se comen las aves encorvadas, ayer era una persona. Quizá cuando ya no pudieron ocultar el olor de la podredumbre, lo sacaron para dejarlo íngrimo en la mitad de su deceso. Un cadáver atravesado en su ruta entre la lavandería y la casa de la Calle Grande (13). 
La estructura textual respeta el modelo descrito en La ciudad y la noche; la mayor parte de los personajes, incluido el protagonista, son o quedan huérfanos; no hay grupos familiares ni parejas; algunos son criminales y otros adictos, como el apodado Fantasma, que había sido investigador y profesor de historia y filosofía y ahora vive en las ruinas del Colegio mendingando cigarrillos. El escenario principal es urbano, en este caso, una ciudad cerrada y encerrada, clausurada para sus propios habitantes, como una especie de cárcel para quienes desobedezcan las órdenes de una cuadrilla temible, la que controla la epidemia. A pesar de la sencillez narrativa, los acontecimientos narrados son trágicos, pertenecen al orden de las calamidades sociales; la conclusión del texto, años después de la epidemia, no mejora la perspectiva: ante una investigación posterior, que trata inútilmente de recuperar el archivo perdido o robado, los protagonistas callan la verdad, algunos mueren o se suicidan y otros, que han armado una vida nueva, prefieren no referirse a la tragedia.

Otro escritor que se convirtió en novelista en los últimos años es el nicaragüense Ramiro Lacayo, quien había estado dedicado principalmente al cine. Decenios antes ya había publicado algunos cuentos y ensayos, de 1984 es su tomo de cuentos Nadie de importancia. Ahora se ha dado a conocer internacionalmente con la novela Así en la tierra, que fue finalista de la trigésimo novena edición del premio Ateneo de Sevilla, en 2007, y la publicó la editorial Uruk dos años después, con una segunda edición en 2010.

Veamos ahora las publicaciones más recientes de los novelistas y cuentistas más conocidos del istmo, que continuaron en esos géneros. La salvadoreña Jacinta publicó dos libros de cuentos: El diablo sabe mi nombre de 2008 y de editorial costarricense, que presenta algunos relatos fantásticos. Crónicas para sentimentales, apareció dos años después, en Guatemala y ganó de los décimos Juegos Florales.

Fuera de El Salvador, Horacio Castellanos Moya continuó su saga acerca de la violencia. Después de la excelente novela Donde no estén ustedes de 2003, publicó en 2004 el tomo de seis cuentos titulado Indolencia y también Insensatez, en la que realiza una 
interesante experimentación lingüística a partir de las lenguas quichés. A estas siguió en 2006 la novela Desmoronamiento, en 2008 Tirana memoria y el año pasado La sirvienta y el luchador.

En Guatemala, de Adolfo Méndez Vides vieron la luz tres libros en 2007, dos novelas y un tomo de cuentos. Las primeras se titulan El leproso y La lluvia; los cuentos están en El tercer patio.

En Costa Rica, Dorelia Barahona ha sido otra de las escritoras que ha estado muy activa; en los últimos años cuenta con cuatro novelas más dos publicaciones en obras colectivas: en 2006 Los deseos del mundo; en 2007 La ruta de las esferas; en 2011 Hotel Alegría y recién presentó la novela Ver Barcelona.

En el género del cuento durante este sexenio se publicaron en Costa Rica dos excelentes libros: La madriguera, de Rodolfo Arias, y La última aventura de Batman, de Carlos Cortés; ambos compartieron el Premio nacional «Aquileo J. Echeverría» de 2010. El primero muestra una cerrada escritura experimental, con claras influencias de Cortázar en varios cuentos. El segundo, en cambio, unifica bajo un estilo fluido los recuerdos de la época juvenil, de familia, colegio, amores.

Antes de agregar más títulos y autores a este bosquejo del mapa de la narrativa reciente del Istmo cabe preguntarse si existe alguna tendencia común, que nos sirva para establecer algunas fronteras. La respuesta que se dé a esta interrogante podría también completar un capítulo de La ciudad y la noche, el que se refiere al tiempo.

En ese libro se planteaba que el tiempo casi exclusivo durante el cual transcurría la totalidad de los acontecimientos de las obras estudiadas era la noche. En una urbe en tinieblas se dibuja un laberinto con las innumerables calles y edificios que las circundan. Aunado a la concentración compacta de la multitud humana, se forma un ambiente que ayuda a la confusión, la escapatoria y el escondrijo de todos, incluidos los criminales. La oscuridad así como la lluvia, la niebla y la ceguera, aumentan la indeterminación del espacio urbano ya que así se impide la distinción de rostros, cuerpos yotras diferencias de las identidades. 
Se hablaba también en La ciudad y la noche de tres tipos de lugares preferidos en estas obras, uno de los cuales se vincula con el tema que estudiamos. Se trata del lugar secreto, que generalmente esconde algún documento u objeto histórico. Podía ser una buhardilla, una habitación clausurada por mucho tiempo, un sistema antiguo de acueductos, una caja con documentos, un armario, en fin, una computadora que guarda información desconocida.

Ahora bien, a partir de 2005 las novelas y los cuentos empiezan a mostrar otro tipo de temporalidad; hemos contabilizado solamente en Centroamérica al menos once novelas y libros de cuentos cuyos acontecimientos se localizan en un tiempo histórico, preferentemente la década de 1950 y la de 1970.

\section{El tiempo y la historia}

Así, a partir de los años que estamos estudiando, buena parte de los novelistas y cuentistas centroamericanos han empezado a interesarse por el tiempo histórico. En Costa Rica, la novela histórica en un sentido tradicional ya había recobrado terreno con las novelas de Tatiana Lobo, publicadas entre 1992 y $2000^{4}$. El asunto ahora es ver cuál es el tratamiento que dan al pasado los escritores nacidos entre 1950 y 1964, quienes no habían publicado prácticamente nada sobre temas históricos. ¿Hay algún cambio, es un nuevo género, acomodan los nuevos personajes a sus temas preferidos?

Del grupo de los autores que estudiamos, en 2007 Dorelia Barahona intentó reunir varios hechos y personajes de la historia de Costa Rica en La ruta de las esferas. Vuelve a los fusilamientos de Juanito Mora y William Walker, la rebelión de los mineros de Abangares y la leyenda de Dulcehé, además del tema de las esferas de piedra del valle del Diquís en la zona sur del país.

4 Asalto al Paraíso en 1992, Calipso en 1996 y El año del laberinto en 2000. 
Con Limón Blues, que ganó el premio nacional de novela y el premio latinoamericano de narrativa José María Arguedas, de Casa de las Américas, Anacristina Rossi había incursionado en una época y un lugar poco o casi nada incluidos en la literatura costarricense: los acontecimientos relativos a la inmigración jamaiquina en la provincia caribeña.

\section{Novelas sobre los setentas}

Con la que se suponía que iba a ser la continuación de Limón Blues, en 2007 aparece Limón reggae de la misma autora, la cual se ocupa de la década de 1970. De la misma época trata la novela Te llevaré en mis ojos, de Rodolfo Arias, que en 2010 ganó el premio nacional de novela «Aquileo J. Echeverría», y Así en la tierra..., del nicaragüense Ramiro Lacayo, publicada un año antes. Los que tenían veinte años en esa década son precisamente los escritores cuyas obras estamos estudiando; en todo el mundo fue una época de activa participación estudiantil en algunas luchas políticas, de protesta y exigencias de cambios, más beligerantes en unos países centroamericanos que en otros.

Así en la tierra...es una de las que mejor ejemplifican el tema histórico en este grupo de escritores ya que sus capítulos se alternan según los años 1969, 1979, 1984 y 2004. El interés por el tiempo se subraya debido a que los hechos narrados transcurren además, en un período de 24 horas, desde las cinco de la mañana de un día de agosto de 1969 a las cinco de la mañana de un día de noviembre de 2004. En la presentación del libro, Sergio Ramírez señala que se trata de los momentos anteriores a tres acontecimientos históricos: antes del terremoto de 1969, al llegar la revolución diez años después y durante la revolución en 1984, todos los tres complementados, dice el escritor, por el último período de 2004. Así en la tierra... parece rendir homenaje a Rayuela, es decir, intentar una rayuela temporal. Como todas las obras de este grupo, empieza en la noche. Se trata al inicio de un grupo de amigos que escriben poesía y frecuentan bares 
y casinos. Hay, además, prostitutas, traiciones, hechos que suceden por casualidad y un final abierto. El sinsentido de la revolución deja sin finalidad el quehacer del protagonista; divorciado, termina abandonado un domingo en la mañana por la joven con quien pasó la noche y quien sí tiene un compromiso político pues desea, al contrario de él, participar en una marcha de campesinos.

El transcurrir de los decenios parece conducir al protagonista desde los sueños juveniles, de proyectos literarios y de pareja, hasta la soledad y la pérdida de ideales. Esta situación existencial se advierte desde muy temprano pues en el primer episodio fechado en 1984 ha crecido la insatisfacción: buscando un taxi en Managua, por ejemplo, detiene a uno cuyo chofer viste una camiseta del Che Guevara; llegan a la Plaza 19 de julio, que «estaba llena de burócratas en trajes verde oliva marchando con fusiles que parecían arcabuces»; pasan frente a «mantas deshilachadas» $\mathrm{y}$, agrega,

Cuando llegué, el día estaba instalado y la casa vacía, huérfana, desamparada. Volví a sentir el amargo sabor del divorcio por diferencias ideológicas en el cual perdí, además de la autoestima, el carro y me dejó una mesa de jugar póquer (...) un televisor ensamblado en Cuba y una cama matrimonial más vacía que la misma casa; donde antes colgaban los cuadros ahora quedaban unas manchas rectangulares, contra la pared un sofá roído por una jauría de chihuahuas de mi exmujer. Y nada más (27-28).

Con el fin de captar la posición ideológica y ética de la perspectiva del texto, es altamente significativo el último episodio de la serie de 1979, cuando Claudio y Moisés ven el ajusticiamiento de un soldado enemigo con el que habían caminado por un trecho del camino. A pesar de que tratan de defender la vida de este y oponerse al fusilamiento sin juicio, el comando sandinista al que lo entregan le dispara por la espalda. 
En el acontecimiento final de los narrados en la serie de 1984, Claudio acompaña el cadáver de un joven que los policías mataron, acusado de atentar contra el «comandante». Después de analizar los hechos llega a la conclusión de que eso es falso y dice: «lo vi solitario en el abandono de la muerte y decidí acompañarlo» (130).

En otro género literario, que goza del favor de estos escritores y también de los guionistas de cine, en 2005 y 2009 aparecen dos novelas policiales que conjugan un enfoque particular de la historia: Mariposas negras para un asesino y El laberinto del verdugo, del costarricense Jorge Méndez Limbrick. Ganadora la primera del Certamen «UNA-Palabra», la segunda mereció dos premios, el de la Editorial Costa Rica y el premio nacional «Aquileo J. Echeverría» de novela. Típicas representantes de la tendencia del grupo de narradores que estudiamos, esperan el tercer tomo para concluir los aconteceres del detective Henry de Quincey y el misterioso Julián Casasola Brown.

En relación con la temporalidad histórica, se puede agregar que, al ambientarse ambos textos en el presente, no se pueden considerar novelas históricas. Sin embargo, también en determinados momentos la acción retrocede temporalmente. En Mariposas negras para un asesino, hay un relato insertado narrado por la voz de Macrón, un herbolario de la época del emperador Augusto. La inclusión de la historia romana permite entonces enlazar todo lo sucedido en un plan suprahistórico, que atraviesa las épocas desde la antigüedad: el texto parece sugerir, por lo tanto, que así como existe una subciudad bajo la ciudad que normalmente todos vemos, a lo largo de los siglos ha habido una cofradía que actúa impunemente, hereda sus leyes y se mueve a través de los continentes.

En la otra novela, El laberinto del verdugo, el tiempo histórico no retrocede tanto sino que se materializa en el archivo del país que cuida el nonagenario Gran Archivero de la Noche, hábil restaurador de libros viejos y exdelincuente adicto a la morfina. Este construyó un laberinto donde guarda la historia no oficial de 
Costa Rica, y este laberinto se llama, como la novela, el «Laberinto del verdugo». El tiempo que se repasa aquí es el de la criminalidad pues los asesinatos de jóvenes en el presente se conectan con otros que se remontan a la primera mitad del siglo xx. Ante la inoperancia de la investigación policial, un periodista y el mismo archivero encuentran las claves en los viejos periódicos y archivos que resguarda el segundo de ellos.

En Guatemala, Oswaldo Salazar había publicado en 2004 Por el lado oscuro. Las acciones se centran en un asesinato ocurrido en 1939, durante la dictadura de Jorge Ubico Castañeda, que gobernó el país entre 1931 y 1944 . Hay en esta novela investigación de fuentes históricas, que se citan en un capítulo final titulado «Afluentes narrativos», si bien la narración se concentra en la investigación policíaca.

\section{Archivo policial}

Un año después sucedió casualmente un acontecimiento en ciudad de Guatemala, que ocasionó la escritura de al menos dos obras en los años posteriores. Fue el descubrimiento del archivo de la policía de Guatemala que apareció gracias a una serie de explosiones del polvorín del ejército guatemalteco y residuos del material bélico utilizado durante la guerra interna que comenzó en 1960 y terminó en 1996. El polvorín estaba dentro de un complejo de edificios policíacos junto con un centro de investigaciones criminales, la perrera policíaca, un hospital abandonado que, según algunos investigadores funcionó como centro de tortura, la academia de la policía, un depósito de vehículos accidentados. En el edificio del hospital se descubrió el Archivo policíaco, oculto en varios cuartos de los primeros dos pisos y otros edificios adyacentes, que estaban repletos de materiales policíacos. Se calcula que son alrededor de ochenta y tantos millones de documentos, incluidos libros de actas de la década de 1890 y que se ocultaron hasta la firma de la paz en 1996. 
Rodrigo Rey Rosa, quien ha publicado en estos últimos seis años dos novelas y dos libros de relatos, se ocupó de este Archivo en la obra que tituló Material humano, de 2009. El mismo lo cuenta en un artículo, en el cual agrega información acerca del llamado Gabinete de identificación. Este estaba oculto bajo un montículo de tierra sobre el cual pasaban las carretillas con los documentos cuando se empezó el ordenamiento del Archivo. Ahí estaban las fichas de identidad policíacas, algunas de las cuales le permitieron ver, solo las fechadas hasta antes de 1970.

Otro relato sobre el mismo hecho es 300 de Rafael Cuevas Molina. Con esta obra su autor cambió el rumbo que llevaba su escritura anterior, seis relatos de corte preferentemente intimista, introspectivo. Con 300 Cuevas ganó el certamen «UNA-Palabra» de 2010. Tanto esta como Material humano son, primero que nada, difíciles de ubicar dentro de un género específico; la de Rey Rosa algunos la consideran una «mezcla de autobiografía, diario, apuntes, citas, historia y ficción ${ }^{5} .300$ es un relato curiosamente estructurado a partir de otros documentos que se publicaron tanto en sitios web como en revistas y periódicos, con el cambio de los nombres propios. Son capítulos, algunos de un solo párrafo, que pertenecen a cuatro categorías establecidas según el tipo de hablantes: los cinco denominados «De la parte de los hechos», en los que se narran los secuestros, es decir, acerca de las víctimas; los seis titulados «De la parte de las razones de la violencia», en los que hablan gente común que trata de encontrar una explicación a lo sucedido. En los cuatro que se titulan «De la parte de los otros-otros» se agrupan fragmentos de anticomunistas, exiliados en Estados Unidos, gente rica. También participan los burócratas que trabajaban en los archivos y policías. Reveladoramente el último capítulo se titula «A mí que me dejen en paz»; se trata, en fin, de un intento de armar el mapa de todos los 
posibles participantes en la terrible represión de ese país durante casi toda la mitad del siglo xx.

Después de esa publicación, en Guatemala también, las novelas y los cuentos que en 2007 lanza Adolfo Méndez Vides se localizan temporalmente en la época del presidente Jacobo Arbenz y el golpe de estado del general Castillo Armas, es decir, en la década de 1950. Como ha hecho en otras ocasiones, el autor desarrolla el tema en un cuento y una novela de formas distintas. La novela es La lluvia y el cuento «El hombre perro», que aparece en El tercer patio, un tomo de seis cuentos. En este relato el tema histórico es tratado aparentemente en un segundo plano, pues la persecución y el apresamiento de un hombre durante la represión después de la caída de Arbenz se narran en medio de la historia del deseo de su hijo de tener y hacerse querer por un perro. El padre, que no vivía en la casa, ha llegado a esconderse perseguido por la policía y la madre lo deja quedarse en una bodega, de donde lo sacan el día de la primera comunión del niño, sin hacer mucho ruido. Así sucede porque la madre está en contra de sus actividades políticas: quiere primero que lo molesten las pulgas en la bodega y luego que nadie se entere que se lo llevan preso. Ambos, madre e hijo, mienten deliberadamente sobre el perro; el niño que se pierde su fiesta, termina herido por los explosivos, sin perro y sin padre.

En la novela La lluvia también hay un episodio similar cuando cae Arbenz y Muñoz, el protagonista, tiene que huir: temeroso de que lo confundan y después de refugiarse en varios sitios, al final los soldados lo dejan salir del zoológico. Pero en realidad él se aprovecha de la confusión general pues no ha cumplido con el pacto inicial en el complot urdido por el arzobispo católico y el gerente de la compañía bananera en Guatemala para asesinar al presidente Jacobo Arbenz. Son los años de 1950; Arbenz era un militar que había subido con un golpe de estado y que sale con otro ejecutado por el general Carlos Castillo Armas en 1954. 
El arzobispo y John Wayne, el empresario gringo, habían convocado a Muñoz a una reunión con el fin de introducirlo en la casa presidencial para que mate a Arbenz. La historia de Muñoz con el presidente alterna con la de su familia en La Antigua. Él no es un joven cualquiera ya que su brazo y su pie tullidos hacen que se lo considere un santo o un sanador, no obstante sus aclaraciones en contra. Constreñido por los que quieren que él sea otro, Muñoz empieza a vivir una vida doble incluso con el mismo presidente, a quien cura sus migrañas con masajes y alcanfor.

La novela abunda en signos dobles; Castillo Armas es llamado «el traidor»; Muñoz tiene dos hermanas, una ciega que depende de su ambiciosa hermana, ambas viven solas en Antigua; al seminarista lo cuidan dos guardaespaldas muy parecidos; el obispo duplica la imagen del Cristo de Esquipulas, que creen milagroso, una versión de bronce y otra de madera, que envían a las fronteras de México y la de Honduras. Finalmente, el carpintero que hace la imagen de madera tiene un hermano gemelo.

El tema del doble acompaña a la figura del traidor; en este texto hay varios: el primero, Castillo Armas, quien traiciona a Arbenz y, sabiéndolo, acompaña a la pareja a pasear por Nueva York. Otro traidor es el mismo Muñoz quien quema la imagen duplicada del Cristo de Esquipulas encargadas por el obispo. De todas maneras en el desfile de la victoria igualmente lo saluda junto con Castillo Armas y ambos le agradecen la colaboración prestada sin saber de su actividad oculta.

La historicidad de La lluvia revela otros hechos del pasado, como el abuso cometido por el dictador Rafael Carrera contra el abuelo marimbista de una mujer de Antigua y una matanza doble que tiene lugar en el pueblo de Patcinzía. Con el relato sobre el general Rafael Carrera, se retrocede temporalmente al siglo XIX, ya que este vivió de 1814 a 1865, derrotó a Morazán en 1837 y asumió la presidencia de Guatemala en 1844 por cuatro años.

Asimismo, la novela contextualiza los hechos locales en la historia mundial mediante la inclusión del entierro simbólico del dictador 
ruso Stalin en Antigua, donde el alcalde encabeza la marcha por las calles con un ataúd relleno de libros que luego incineran. Curiosamente Muñoz comparte con Stalin varios rasgos: este de niño padeció viruela, por lo que le quedaron marcas en la cara mientras que Muñoz tiene marcas de viruela en la frente por no haber sido tratada bien cuando era niño. Al igual que Muñoz, Stalin estudió en un seminario teológico, de Tífilis, de donde lo expulsaron; murió casi en los mismos años del gobierno de Arbenz, en febrero de 1953, año en que también terminó la guerra coreana y se enfriaron más las relaciones entre los Estados Unidos y la Unión Soviética, hecho que también se menciona en La lluvia así como el clima de macartismo que hace rodar las leyendas anticomunistas difundidas por la CIA para preparar el golpe contra Arbenz.

El cambio de gobierno coincide con la muerte del padre de Muñoz, quien fallece media hora antes de la medianoche el día de su cumpleaños. Después de saludar a Castillo Armas, Muñoz asiste con sus hermanas a la frugal cena familiar; juntos deciden ocultar la hora de la muerte del progenitor para no pagar de más a la funeraria; recogen los restos de la cena, cierran la casa y dejan al muerto solo.

Dos grandes novelas de Horacio Castellanos Moya se publicaron en este sexenio. Con estas se completa y se cierra la trilogía que inició en 2006 con la titulada Donde no estén ustedes. Tirana memoria, de 2008, marca en la carrera del autor un radical cambio estilístico y una nueva posición, un giro de trescientos sesenta grados, sobre la mujer ya que desaparecen las mujeres-objetos-sexuales que predominaron en sus relatos anteriores. También en La sirvienta y el luchador de 2011 los personajes femeninos tienen una mayor participación, por ejemplo, María Elena, cuya perspectiva guía el relato y participa activamente hasta el final, y también su hija Belka.

En Tirana memoria hay dos narradores, una es Haydée, mujer casada con hijos, que escribe un diario en el que cuenta los acontecimientos relativos al secuestro de su esposo. Su relato trata de imitar la detallista forma de hablar de una mujer de su condición de tal manera que llega a convertirse casi en una narración minimalista, que no aburre, al contrario, 
interesa y hace desear al lector continuar la lectura sin detenerse. Este efecto aumenta con el otro narrador, neutro, que cuenta en forma alternada la huída de uno de los hijos de Haydeé y que sabiamente suspende la narración en los momentos álgidos, para crear mayor suspenso.

El periodista secuestrado se oponía al «Brujo», apodo con el que se llamaba al dictador Maximiliano Hernández Martínez porque tenía creencias teosóficas. Este gobernó El Salvador entre 1931 y 1944, murió en 1966 y había sido, además, el responsable de la matanza de 25.000 campesinos en 1932. Todo esto se evoca en la novela, así como el hecho principal cuando en 1944, un grupo de militares se alzó contra el presidente y fueron duramente reprimidos en pocos días. Un mes después se suscitó una huelga general de la sociedad civil, la cual obligó al general a deponer el cargo de la primeramagistratura.

El relato de Haydeé recrea día a día la organización de los familiares de los presos, entre los cuales ella misma, que poco a poco pasan del miedo o la indiferencia políticas a posiciones más activas y organizadas contra el militar que los reprime cada vez más. Se trata de estudiantes pero también de familias pudientes, de cafetaleros que incluyen militares y señoras de bien, incluso, excolaboradores de Hernández Martínez, como el esposo de Haydeé en el pasado o uno de los hijos de ambos, alcohólico y mujeriego y luego pieza clave en el primer intento de insurrección.

El Brujo nunca aparece como personaje, solo lo mencionan los otros; poco a poco todos lo abandonan, empezando por el periodista Pericles, que se convirtió en un férreo opositor y termina en las cárceles del dictador fantasma. Al final de la novela, treinta años después de estos hechos, su mejor amigo pinta a Pericles como un ángel caído. Todos estos datos acercan la novela de Castellanos a $E l$ señor Presidente, de Miguel Ángel Asturias, tanto por la presencia del dictador fantasma como por su fiel ayudante Miguel Cara de Ángel, que termina en las profundidades de las mazmorras cuando ha perdido la gracia de su «padre».

La historia de la familia Aragón se vuelve a recuperar en la tercera novela de este ciclo, La sirvienta y el luchador, publicada el año 
pasado. En esta reaparecen algunos de los descendientes y también otros personajes que habían estado en un segundo plano, como la empleada doméstica de la familia, que resulta coprotagonista en algunas partes. Todos se entremezclan en un violento escenario en el que participan además los esbirros encargados de secuestros de oponentes políticos, como el apodado Vikingo, un viejo luchador quien, a pesar de estar enfermo de muerte, no quiere abandonar el sucio trabajo.

Los acontecimientos de esta novela se localizan temporalmente en 1980, se centran en el secuestro, la tortura y el asesinato del militante comunista Roberto Castellanos y su esposa danesa Anette, que en la novela se llaman Betico y Brita; él no aparece en Tirana memoria, aunque sí en Donde no estén ustedes.

En ese contexto, los acontecimientos narrados en Tirana memoria se encadenan gracias a la casualidad, por ejemplo, poco a poco se descubre que Vikingo era el encargado de vigilar a Pericles en 1944 y ahora es uno de los secuestradores de su nieto. En el pasado había también pretendido a María Elena, la empleada doméstica de la familia Aragón, quien el día del secuestro empezaba a ayudar en la casa del nieto. Al reconocerlo, en La sirvienta y el luchador ella es quien identifica a Vikingo y lo busca para confirmar el secuestro.

En la segunda parte de la novela este complejo nudo de acciones azarosas se complica ya que los acontecimientos se narran mediante las múltiples perspectivas que ofrecen los nuevos personajes que van apareciendo, cada uno de los cuales narra una parte de la acción. También sucede que en algunos momentos haya una narración simultánea, lo cual confiere un eficaz efecto de velocidad.

Se trata de la guerra en acción, con el relato de las batallas, los ataques y los operativos de ambos bandos; los heridos, los muertos y los presos; secuestros en los hospitales, la entrada en la fortaleza (ciudad). Recordemos que 1980 se considera un año álgido en la historia reciente de El Salvador. Empezó con el asesinato del procurador de la República, Mario Zamora Rivas, un mes después el del Arzobispo de San Salvador, monseñor Óscar Arnulfo Romero; en mayo, la violenta masacre de más 
de 600 personas en el río Sumpul en la frontera con Honduras; y en diciembrela violación y el asesinato de cuatromonjas estadounidenses por efectivos de la Guardia Nacional. Fue 1980 también el año de la formación del Frente Farabundo Martí para la Liberación Nacional $(\mathrm{fmLn})$ gracias a la alianza de varias organizaciones. En enero de 1981 el fmLn lanzó una ofensiva general con el llamado a una insurrección a nivel nacional, acción que sirvió como detonante de la guerra civil subsiguiente. Desde el otrolado hubo grupos paramilitares, escuadrones militares especiales y la fundación del partido de derecha Alianza Republicana Nacionalista, Arena. Lajunta militarque teníael poderen esos años recibió ayuda del gobierno de Estados Unidos que se calcula quellegó a 1.000 millones de dólares.Las conversaciones de paz se iniciaron en 1989; se firmaron varios acuerdos y protocolos entre 1990 y 1992, aunqueenmediode estas conversacionesse asesinóa seisjesuitas vinculados con la teología de la liberación y el fmLn lanzó una ofensiva nacional.Esta violentaguerra de doceaños de duracióncausólapérdida de más de 75.000 civiles y alrededor de 9.000 desaparecidos.

En la novela, se mezclan las posiciones políticas dentro de una misma familia, por ejemplo, las de María Elena, su hija Belka y el hijo de esta. La primera afectivamente está con la familia Aragón; Belka, por necesidades económicas y ambiciones profesionales, termina involucrada con los militares. Su propio hijo, finalmente, quien milita con el Frente Farabundo Marí es uno de los responsables de tirotear el jeep donde viaja su madre en el primer trabajo.

Antes del epílogo, María Elena y Vikingo conversan en el hospital y atan varios cabos sueltos. Sin embargo, el final es abierto: la novela empieza y termina con los torturadores, al inicio cuando van a comer donde Rita, al final cuando entierran a la pareja Castellanos. No se dilucida si Vikingo murió o no, si Belka sí se hirió.

¿Cómo se unen las tres novelas? En Donde no estén ustedes se había relatado el asesinato de Alberto Aragón hijo pero dentro de la remembranza de la vida de su padre durante sus últimas semanas en México. En Tirana memoria se retrocede a la historia de Pericles, 
padre de Alberto; en la tercera se llega a la década de 1980, en unos días específicos, a la muerte del nieto de Pericles. Así, la familia Aragón de las tres novelas y algunos allegados, amigos o empleados, sirve como nudo a partir del cual la escritura teje una compleja trama de relaciones secretas y de traiciones. Son cuarenta años que se intentan novelar para tratar de descubrir en su imbricado tejido una historia, la historia de una violenta guerra sucia y el final de una familia.

Para finalizar, me interesa incluir una reciente novela de un escritor que, si bien es mucho más joven que los anteriores, publicó un relato que coincide no solo en uno de los géneros preferidos de aquellos -el relato policíaco - sino que además de tratar un hecho histórico, de alguna forma responde a la interrogante lanzada por los escritores anteriores a él. Se trata de Verano rojo, de Daniel Quirós, ganador del Premio nacional «Aquileo J. Echeverría», en novela en Costa Rica en 2010.

A pesar de la diferencia de edad del autor (nacido en 1979), esta novela comparte muchos rasgos con las del grupo anterior (los nacidos entre 1950 y 1963). Se trata de una policíaca, con investigadores y crímenes. Estos se desarrollan en el contexto histórico-político centroamericano, tal como hacían Cruz de olvido, de Carlos Cortés y los relatos de Óscar Núñez. Sus personajes son, también como en las anteriores, huérfanos y solitarios: un exinvestigador de seguros y excombatiente de la guerra nicaragüense, que vive solo en un pequeño pueblo de la costa Pacífica, al igual que su amiga Ilana Echeverri, conocida como la Argentina. Su asesino es un individuo más solitario aún, que había sido compañero de luchas de Ilana en Argentina.

Se añaden, sin embargo, dos elementos novedosos, que separan esta novela del modelo anterior: por un lado, la acción no transcurre en una ciudad sino en pequeños poblados y en el campo; el protagonista, incluso, explica que vivir en el campo fue su propia decisión, harto de la vida urbana, con el propósito de «fomentar el olvido» ${ }^{6}$.

6 No obstante, no deja de notarse el crecimiento urbano, pues como se aclara en el mismo texto, el lugar donde transcurren varios hechos pasó de un pueblo de 400 personas a «una ciudad de más de siete mil» (p. 15) y entre estos no solo locales guanacastecos (p. 66). 
En medio de la profunda oscuridad del campo, los potreros y las playas sin luna, un excombatiente de la guerra de Nicaragua de 1979 debe aprender a leer las complicadas claves de una amiga suya, recientemente asesinada, para saber quién la mató. Ambos, de casi sesenta años de edad, se habían hecho amigos porque eran de los pocos que les interesaban los libros en los remotos pueblos donde vivían. Cuando ella muere, Chepe se siente en la obligación moral de encontrar al asesino y empieza a buscar las pistas escondidas en los dobles signos de fotos, noticias y cartas que ella le deja en diversoslugares.

En las fotos aparece la mujer con otros hombres, en algún lugar de Buenos Aires y Managua. Cuando las ve, el narrador comenta sobre la cercanía histórico-geográfica de «aquella época, que yo también había vivido, que nunca volvería a acontecer» (p. 40). Todos los documentos Chepe los siente como un «laberinto sin nombre» (p. 41) al que, en honor de la amistad, se siente obligado a entrar. De esta manera, él, la víctima y el asesino forman parte de un tiempo y un compromiso político que terminan en eso, el gesto mercenario y la traición, en un olvidado pueblo de un desconocido país.

Verano rojo obliga a su lector a meterse de lleno y de nuevo en los documentos acumulados a lo largo de 25 años después de los sucesos de La Penca, el 30 de mayo de 1984. Esto se utiliza para articular la novela en la realidad histórica mediante acontecimientos que podrían haber ocurrido, es decir, se inserta en un verosímil y al hacerlo, de alguna forma saca a Costa Rica de su aislamiento internacional y la inserta dentro de una geopolítica internacional.

Recordemos que el acontecimiento histórico referido en este relato es el atentado organizado contra Edén Pastora, que acabó con la vida de varias personas que asistían a una conferencia de prensa convocada por el líder nicaragüense. Esto ocurrió en un lugar en la frontera entre Costa Rica y Nicaragua el 30 de mayo de 1984. Hubo varias investigaciones; por ejemplo, el libro de los periodistas norteamericanos Martha Honey y Tony Avirgan, y el documental que el año pasado Peter Torbiörnsson, periodista sueco, presentó en Nicaragua y CostaRica. 
Con el nombre de Peter Olson el periodista sueco aparece en la novela, ya que esta se construye sobre la base de la historia reciente latinoamericana; algunos hechos son verificables así como varios nombres de personajes recuerdan los nombres reales de los personajes históricos, por ejemplo, el del asesino Roberto Vital Gaguine que en la novela resulta Gandini.

Aunque la reproduce, la literatura también se permite jugar con la historia: se imaginan personajes, destinos y muertes sobre el trasfondo histórico sin que ambas líneas se contradigan.

Con lo anterior contrasta la curiosa mirada externa con que se ven y se narran los hechos: aunque se narre en primera persona, el relato mantiene un tono objetivo, neutral, externo: entonces nos preguntamos si la literatura vuelve acaso a ser medio de revelación de una verdad, un medio de denuncia social. Pero si es así, quien narra se preocupa de denunciar aunque sin involucrarse, de mantenerse fuera de los hechos, sin expresar el menor sentimiento o una determinada valoración subjetiva.

De eso se deriva el interés por el desciframiento de documentos: esta forma de entender lo sucedido reduce al mínimo el contacto personal; se trata, en fin, de un ejercicio mental, así como el aparato de GpS transmite coordenadas para llegar finalmente al escondite del asesino.

La continua lectura de documentos no es un detalle insignificante, todo lo contrario, es altamente significativo pues conduce a una visión de la literatura, de la literatura de este nuevo grupo de escritores. La escritura escoge un tema político e histórico y lo moldea dentro de las posibilidades que ofrece el género policial.

En el triángulo que se establece entre víctima, asesino e investigador, Gandini también encarna al traidor y eso es el motivo por el cual Chepe lo persigue hasta encontrarlo y verlo muerto. «En algún momento fui de los buenos, ahora estoy demasiado viejo y cansado para saber», dice Chepe al periodista sueco en Liberia (p. 81). Si Chepe se jubiló antes de tiempo, podría tener ahora aproximadamente cincuenta y cinco años, lo cual significa que nació en la década de 1950. De acuerdo con 
esto, ¿es la intención de Verano rojo desenterrar la historia que el grupo anterior no quiso o no pudo revelar? Recordemos que uno de los tres tipos de sitios preferidos de estos era el lugar secreto, el cual generalmente contenía documentos de valor histórico.

En Verano rojo se resuelve un acontecimiento del pasado al tratar de solucionar un asesinato del presente. De esta forma la novela de Daniel Quirós recoge e interroga las noticias pretéritas que algunos no quisieron cerrar y otros no tuvieron la voluntad de resolver después de veinticinco años. Sobre el tejido de la historia, la literatura teje otro texto, lo amarra al primero y completa así los vacíos, que no habían completado sus protagonistas. Por eso la primera pista es una carta que imita la carta de un escritor a otro escritor. En Verano rojo se encuentra y se identifica al asesino, al traidor, se lo acorrala hasta su muerte. Y el que lo lleva a cabo no es un joven de treinta años sino un jubilado de casi sesenta.

Quienes lo acompañan en la siniestra y peligrosa aventura son sus coetáneos, una hippie sudamericana exguerrillera y un exguerrillero traidor (ver p. 115): aún muerta, ella conduce al investigador con una llave y varios documentos hacia las pistas que finalmente le ayudarán a descifrar el curso de los acontecimientos, el suyo propio y el del pasado compartido. Solo así se podrá ver la luz de las llamas. El texto literario vuelve a ser instrumento para revelar una verdad histórica, para la denuncia política.

\section{Conclusión}

En el epígrafe de Tirana memoria se citan las siguientes palabras de Elias Canetti:

¿No sería más correcto que no quedase nada de una vida, absolutamente nada? ¿Que la muerte significase extinguirse de pronto en todos los que retengan alguna imagen de uno? ¿No sería más cortés frente a los que vendrán? Pues tal vez todo lo que queda de nosotros constituye una exigencia que les abruma. Quizá por eso no es libre el 
hombre, porque queda demasiado de los muertos en él, y ese mucho se resiste a extinguirse.

El escritor reconoce la imposibilidad de huir del pasado, de la memoria de los muertos. La escritura, en consecuencia, es una forma de conjuro contra esa esclavitud de la memoria, del recuerdo, de ahí el título de la novela de Castellanos.

La inserción de una temporalidad de carácter histórico en la narrativa del istmo en este grupo de escritores muestra un nuevo interés pero a la vez una gran dificultad para manejarlo. La conclusión del acontecimiento histórico en La lluvia de Méndez Vides no se narra y la novela finaliza con los hechos relativos a la familia del protagonista. Este, sea o no un ser ficticio, no es definitivamente la figura de la historia de Guatemala.

Tanto en Material humano, en el relato de Rafael Cuevas y en Así en la tierra..., el tiempo histórico se fragmenta en un mosaico narrativo. Algo semejante ocurre en la trilogía de Castellanos Moya en la cual, además, como en casi todas, los hechos históricos se mezclan con otros inventados. Podría pensarse que la cantidad de años que median entre la publicación de la primera Donde no estén ustedes, 2003, y el cierre del ciclo, 2011, es decir, la narración completa del asesinato de Roberto Castellanos, expliquen parcialmente por qué estas sean los únicos textos narrativos lograron incorporar y darle sentido pleno al hecho histórico.

Por eso llama la atención el relato de Daniel Quirós: quizás por ser un escritor nacido en otra década y tal vez también por el hecho de vivir fuera de Centroamérica pudo mirar con mayor distancia la reciente historia que los demás solamente pudieron percibir escondida en lugares secretos.

En una noticia reciente se informaba que algunos países centroamericanos viven en medio de una violencia extrema que sigue creciendo: el índice de homicidios por persona en Guatemala y Honduras es superior al de México, pues mientras que en este país es de dieciocho 
personas por cada 100.000 habitantes en Guatemala y Honduras llega a cuarenta y un homicidios anuales por cada 100.000 personas.

La narrativa ha sabido leer este mapa social desde hace más de veinte años y ha lanzado serias advertencias. No se trata solamente de los narcotraficantes, como dicen ahora los periódicos; los relatos que hemos mencionado hablan de otras guerras, la del pasado reciente. Por esa razón se equivocan los que hablan de «narrativa de la posguerra». Esta es la literatura de la guerra, se trata de relatos que intentan dar un significado a ese terrorífico tiempo que se vivió principalmente en tres de los siete países centroamericanos. Porque se estén escribiendo después de esos años no quiere decir que sean de la «posguerra»; al contrario, son de la guerra porque hablan de esa violencia.

Los años que empiezan a aflorar constituyen un «círculo infernal y demoníaco», en palabras de Johan Huizinga, en su clásico libro sobre el juego. En este explica que, «en ninguna parte es tan imprescindible el mantenimiento de las reglas del juego como en las relaciones entre pueblos y estados. Cuando se violan, la sociedad cae en la barbarie y en el caos»?

Eso fue lo que hicieron durante esos años, los ejércitos, los militares y las policías de Guatemala, El Salvador y Nicaragua, con la complicidad y ayuda permanente de los gobiernos de Estados Unidos. Rompieron las reglas que sostenían el equilibrio y con esto destruyeron esas sociedades. Se trata ahora de entender por qué; eso trata de descifrar la literatura contemporánea del istmo.

7 J. Huizinga, Homo ludens (1938; nueva edición en español: Madrid: Alianza, 1998) 248. 